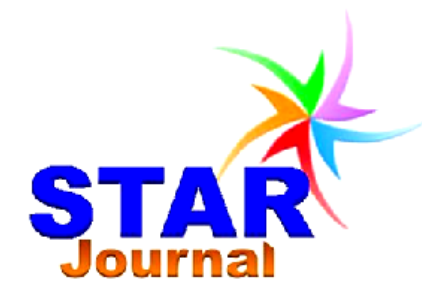

ISSN: 2226-7522(Print) and 2305-3327 (Online) Science, Technology and Arts Research Journal

Jan-March 2012, 1(1): 60-64

www.starjournal.org

Copyright@2012 STAR. All Rights Reserved

General Perspective

\title{
Gender Perspectives in Language
}

\author{
Deepika Nelson ${ }^{*}$ and Julia Devardhi
}

School of Foreign Language Studies, Haramaya University, Ethiopia

\begin{abstract}
Gender is multi-faceted, always changing, but often contested. It is embedded in our institutions, our actions, our beliefs, and our desires, that it appears to us to be completely natural. Gender is, after all, a system of meaning -- a way of construing notions of male and female and language is the primary means through which we maintain or contest old meanings, and construct or resist new ones. This paper discussed the relationship of gender perspectives in language with special emphasis on Sociolinguistic Patterns of Class, Style, and Gender and the Approaches of Social constructionist.
\end{abstract}

Key words: Gender, Language, Sociolinguistic, Constructionist

\begin{tabular}{l}
\multicolumn{1}{c}{ Article Information } \\
\hline Article History: \\
Received : $14-01-2012$ \\
Revised : 08-02-2012 \\
Accepted : 15-02-2012 \\
\hline \\
*Corresponding Author: \\
Deepika Nelson \\
E-mail: dr.deepikanelson@gmail.com \\
Phone: +251923203250
\end{tabular}

\section{INTRODUCTION}

Gender and Language can be defined in many ways. First, gender is a key element of social relationships often loosely linked to perceived differences between the sexes. Gender relations are encoded in linguistic and symbolic representations, normative concepts, social practices, institutions and social identities. Secondly, gender is a primary arena for articulating power, intersecting in complex ways with other axes of inequality, like class, race, and sexuality. Gender is understood as multi-faceted, always changing, and often contested.

We may attempt at an equally comprehensive definition of language: a language is what the members of a particular society speak. However, as we will see, speech in almost any society can take many very different forms, and just what forms we should choose to discuss when we attempt to describe the language of a society may prove to be a contentious matter. Gender is embedded meticulously in our institutions, our actions, our beliefs, and our desires, that it appears to us to be completely natural. Gender is not something we are born with, and not something we have, but something we do (West and Zimmerman, 1987) -something we perform (Butler, 1990). The world swarms with ideas about gender -- and these ideas are so commonplace that we take it for granted that they are true, accepting common adage as scientific fact. In this paper "Gender Perspectives in Language" we focus on the different ways in which men and women use language and how the structure of language reflects and/or promotes gender division within a society.

Early studies of interruptions, such as Zimmerman and West (1975), were based on the assumption that interruption is a strategy for asserting conversational dominance and that conversational dominance in turn supports global dominance. And underlying studies of amount of speech (Swacker, 1975) was the desire to debunk harmful female stereotypes such as the "chattering" woman. But as time went on, the study of difference became an enterprise in itself and was often detached from the wider political context. Deborah Tannen's explicit "no-fault" treatment of difference (1990) is one of the most prominent examples.

In the famous words of Simone de Beauvoir, "Women are not born, they are made". The 
making of a man or a woman is a never-ending process that begins before birth - from the moment someone begins to wonder if the pending child will be a boy or a girl. The enormous differences among men and women based on factors such as class, race, ethnicity, religion, and region have also led scholars to question whether the term "women" (and by extension "men") is a valid analytical category, or whether these differences are so great that there really is nothing that could be labeled "woman" whose meaning is self-evident and unchanging over time. Not only in the present is gender "performative," that is, a role that can be taken on or changed at will, but it was so in the past, when individuals challenged existing gender roles or when, based on the individual's class or racial status, he or she was not viewed as included in the category of "men" or "women."

The work by Ann Bodine (1975) who traced the quite deliberate legislation of the use of masculine generics in English in the nineteenth century, Sally McConnell-Ginet (1984) traced the relation between semantic change and the power dynamics of the everyday use of words, and Paula Treichler (1989) traced the power dynamics involved in the inclusion of words and definitions in the great arbiter of linguistic legitimacy

\section{Sociolinguistic Patterns of Class, Style, and Gender}

Deborah Cameron's (1985) Feminism and Linguistic Theory argued that the standard linguistic focus on a static linguistic system obscured the real gender dimensions of language. The language which emerges from the sociolinguistic study of metropolitan dialects is that of a structured but unpredictable system, whose use is conditioned by both internal and external factors. A major finding of metropolitan sociolinguistic work is that differences among social dialects are quantitative and not qualitative. Thus, all speakers tend to make use of the same linguistic features. The connection of social and stylistic is one of the most important findings of quantitative sociolinguistics, i.e, if a characteristic occurs more frequently in working-class speech, then it will occur more frequently in the informal speech of all speakers

Nordberg (1971) proposed that this pattern of sex differentiation is so ubiquitous in Western societies today that it could almost serve as a criterion for determining which speech forms are stigmatized and which carry prestige in a community. Sociolinguists often invoked explanations based on women's supposed greater status consciousness, greater awareness of the social significance of variants, and concern for politeness. When asked to say which forms they used themselves, African women, for instance, claimed that they used more standard forms than they actually did. Men, however, were likely to under-claim their use of standard forms. When we turn to certain grammatical matters in English, we find that Brend (1975) claims that the intonation patterns of men and women vary somewhat, women using certain patterns associated with surprise and politeness more often than men.

Lakoff (1973) too says that women may answer a question with a statement that employs the rising intonation pattern usually associated with a question rather than the falling intonation pattern associated with making a firm statement. According to Lakoff, women do this because they are less sure about themselves and their opinions than are men. For the same reason, she says that women often add tag questions to statements, e.g., 'They caught the robber last week, didn't they?' These claims about tag questions and insecurity have been tested by others (Dubois and Crouch; 1975, Cameron et al., 1989; and Brower et al., 1979) and found wanting: experimental data do not necessarily confirm intuitive judgments. The latter investigators did find, however, that the gender of the addressee was an important variable in determining how a speaker phrased a particular question. Thus, women may be using linguistic means as a way to achieve status denied to them through other outlets. Since women have long been denied equality with men as far as educational and employment opportunities are concerned, these are not reliable indicators of a woman's status or the status she aspires to.

Another dichotomy that emerged in the study of language and gender is the one between how women and men speak, and how they are spoken of. It was often thought that the study of people's use of language was quite separate from the study of the embedding of gender in language. After all, the speakers did not make the language. This separation was supported by the academic linguistic canon, which viewed language as a system beyond the reach of those who use it. Thus the fact that expressions referring to women commonly undergo 
semantic derogation was viewed as merely a linguistic fact.

Gender and Language theorists of the 1970s and 1980s who were adherents of the '(male) dominance' (retrospectively labelled) approach would probably see gendered discourse as referring to the nature of the interactional dominance which they found in mixed-sex conversations: Fishman (1983), West and Zimmerman (1983) and Edelsky (1977) showed men on the whole talking more than women, interrupting more, providing fewer minimal responses, asking fewer questions, and having their topics taken up more regularly. Discourse was becoming prominent on the language side, there was a shift in feminist theory and gender studies in thinking about gender. As Cameron (1998a) observed, the years since the early days have seen a shift in language and gender research from the search for correlations between linguistic units and social categories of speakers to analysis of the gendered significance of ongoing discourse. What we can call for short the "discourse turn" in language and gender studies emphasizes both the historical and dynamic character of language, and the interactive dimensions of its use. The "discourse turn" need not mean that we ignore linguistic units like speech sounds or words, but it does require that such units be considered in relation to the functions they serve in particular situated uses, and it also requires that the units themselves not be taken as fixed and immutable. Cameron (1998b) states that view in a slightly different way:

Men and women . . . are members of cultures in which a large amount of discourse about gender is constantly circulating. They do not only learn, and then mechanically reproduce, ways of speaking 'appropriate' to their own sex; they learn a much broader set of gendered meanings that attach in rather complex ways to different ways of speaking, and they produce their own behavior in the light of these meanings. . . .

Performing masculinity or femininity 'appropriately' cannot mean giving exactly the same performance regardless of the circumstances. It may involve different strategies in mixed and single -sexed company, in private and public settings, in the various social positions (parent, lover, professional and friend) that someone might regularly occupy in the course of everyday life.
Gender is also something we cannot avoid; it is part of the way in which societies are ordered around us, with each society doing that ordering differently. As Eckert and McConnell-Ginet (2003) say: 'The force of gender categories in society makes it impossible for us to move through our lives in a non gendered way and impossible not to behave in a way that brings out gendered behavior in others.' Gender is the key component of identity.

\section{Style is the Woman}

Our place in the gender order constrains our acts, but at the same time it is our acts (and those of others) that place us in the gender order and that bring the different aspects of gender into being. While social structure and available resources provide constraints, it is people who decide just how constrained they will allow themselves to be. And these decisions are not made simply with reference to gender, but with reference to all the other aspects of our being that interact -- often unknown to us -- with gender. A person's style is not static -- it emerges in social practice, and involves an ongoing history of stylistic moves. When we talk about style, we are talking about a process that connects combinations of elements of behavior with social meaning. People are continually engaging in stylistic practice. Every act is by definition a stylistic act, and our continual invention of ourselves is a continual stylistic enterprise. In as much as people feel that their way of speaking defines them, the development of linguistic style is a central part of identity work. Individuals or communities of practice may engage frequently, or habitually, in particular patterns of moves and activities, yielding a discursive style. It is at the level of style that people are judged.

\section{Social Constructionist Approaches}

Recent research on the relationship between language and gender has been dominated by approaches that examine the ways in which gender is socially constructed in interaction, rather than existing as a fixed social category to which individuals are assigned at birth (Crawford 1995; Hall \& Bucholtz 1995; Bergvall et al., 1996; Bucholtz et al., 1996).The social constructionist approaches in Cameron's words (1992:13),: encourages a different focus: "not gender differences but the difference gender makes." Instead of abstracting gender from social practice, they note the need to focus on "gender in its full complexity: how gender is constructed in social practice, and how this construction intertwines with that of other 
components of identity and difference, and of language" In other words, the patterns, generalizations, and norms of speech usage which emerge from quantitative analyses provide a crucial framework which informs and illuminates the ways in which individual speakers use language. Meyerhoff concludes that the notions of a speech community and intergroup distinctiveness account most appropriately for the distribution of apologies in women's and men's speech in Vanuatu (South Pacific).

\section{CONCLUSION}

Gender and language had been linked in scholarly writings well before the second wave of the Women's Movement began in the late 1960s and early 1970s. Languages are just as complex as societies, and we all know how difficult it is to make generalizations about those. Languages should be so complex is not surprising. Languages and societies are related and social and linguistic complexities are not unrelated. Women's and men's speech has been of particular interest to sociolinguists. Issues include gender-differential tendencies in style-shifting (for example, between formal and casual speech), use of prestige and stigmatized variants, linguistic conservatism, who leads language change and the positive and negative evaluation of such change.

Language figures in all of these developments. But language is never the whole story because the linguistic toolbox is so rich and varied. All we can say about gender and language that way will continue to change. And they will continue to be intertwined in social practice, perhaps in ways we do not now foresee.

\section{REFERENCES}

Bergvall, V. L., Bing, J. M. and Freed, A. F. (eds.) (1996). Rethinking Language and Gender Research: Theory and Practice. London: Longman.

Bodine Ann. (1975). Androcentrism in prescriptive grammar: singular "they," sex-indefinite "he," and "he or she." Language in Society 4: 129-146.

Brend, R. (1975). Male-Female Intonation Patterns in American English. In: Thorne and Henley.

Bucholtz, M. (1999). You Da Man: Narrating the Racial Other in the Production of White Masculinity. Journal of Sociolinguistics 3(4): 44360.
Bucholtz, M. and Hall, K. (2004). Theorizing Identity in Language and Sexuality Research. Language in Society 33: 469-515.

Butler., Judith. (1990). Gender Trouble: Feminism and the Subversion of Identity. New York and London: Routledge.

Cameron Deborah. (1992). "Not gender differences but the difference gender makes": Explanation in research on sex and language. International Journal of the Sociology of Language 94: 13-26.

Cameron, D. (1992). Feminism and Linguistic Theory. $2^{\text {nd }}$ edn. London, Macmillan.

Cameron, D. (1998a). Gender, Language, and Discourse: A Review Essay. Signs: Journal of Women in Culture and Society, 23(4): 945-73.

Cameron, D. (1998b). Performing Gender Identity: Young Men's Talk and the Construction of Heterosexual Masculinity. In: Coates.

Cameron, D. (1998c). The Feminist Critique of Language: A Reader. $2^{\text {nd }}$ edn. London, Routledge.

Cameron, D. (1996). The Language-Gender Interface: Challenging Co-option. In: Bergvall et al. (1996).

Cameron, D. (1997). Demythologizing Sociolinguistics. In: Coupland and Jaworski (1997).

Crawford, J. (1992a). Hold Your Tongue: Bilingualism and the Politics of 'English nly.' Reading, MA: Addison-Wesley.

Crawford, M. (1995). Talking Difference: On Gender and Language. London: Sage.

Dubois, B. L. and Crouch, I. (1975). The Question of Tag Questions in Women's Speech: They Don't Really Use More of Them, Do They? Language in Society 4: 289-294.

Dubois, S. and Horvath, B. (1999). When the Music Changes, You Can Change Too: Gender and Language Change in Cajun English. Language Variation and Change 11(3): 287-313.

Eckert, P. and McConnell-Ginet, S. (2003). Language and Gender. Cambridge, Cambridge University Press

Eckert, P. (1997). Age as a Sociolinguistic Variable. In: Coulmas (1997).

Edelsky, C. (1977) 'Acquisition of an aspect of communicative competence: learning what it means to talk like a lady', in Susan Ervin-Tripp and Claudia Mitchell-Kernan (eds) Child Discourse. New York: Academic Press.

Freed, A. F. (2003). Epilogue: Reflections on Language and Gender Research. In: Holmes and Meyerhoff (2003).

Labov, W. (1966). The Social Stratification of English in New York City. Washington, DC: Center for Applied Linguistics.

Labov, W. (1970). The Study of Language in its Social Context. Studium Generale, 2330-87. In: Fishman (1971-2, vol. 1), Giglioli (1972), and Pride and Holmes (1972). 
Labov, W (1972). Sociolinguistic patterns. Philadelphia: University of Pennsylvania Press

Lakoff, R. (1973). Language and Woman's Place. Language in Society 2: 45-80.

Meyerhoff, Miriam, \& Niedzielski, Nancy (1994). Resistance to creolization: An interpersonal and intergroup account. Language and Communication 14: $313-30$

Romaine, S. (2001). Language in Society: An Introduction to Sociolinguistics. $2^{\text {nd }}$ edn. Oxford, Oxford University Press.
Swacker, M. (1975). The sex of speaker as a sociolinguistic variable.In: Thorne and Henley (1975) 76-83.

Tannen, D. (1990). You Just Don't Understand: Women and Men in Conversation. New York, William Morrow.

Tannen, D. (1994). Gender and Discourse. New York, Oxford University Press.

Treichler Paula, A. (1981). Verbal subversions in Dorothy Parker: "Trapped like a trap in a trap." Language and Style, 13: 46-61. 